\title{
Education and Science
}

Vol 41 (2016) No 184 49-58

\section{Leadership Behavior of Deans And Its Impact on Effectiveness for Quality in A High Ranking University *}

\section{Sailesh Sharma ${ }^{1}$, Syed D. S. Amir ${ }^{2}$, Jeyasushma Veeriah ${ }^{3}$, Sathiamoorthy Kannan ${ }^{4}$}

\begin{abstract}
This paper examines the effects of leadership behavior of deans on their university's academic and scholarly development policies. Using a sample of 400 faculty members across eight faculties, a selfdeveloped questionnaire was administered to examine the deans' leadership behavior its effectiveness on the quality of their policies. The results indicate that the leadership behavior in this research university is linked with different dimensions of effectiveness for quality.
\end{abstract}

Keywords

Leadership behavior

Quality effectiveness

Research university

Malaysia

Article Info

Received: 18.10.2015

Accepted: 03.04.2016

Online Published: 27.04.2016

DOI: 10.15390/EB.2016.6071

\section{Introduction}

The higher education sector in Malaysia has undergone tremendous change over the past five years. With the introduction of its highly ambitious and influential blue print in 2015, the Ministry of Higher Education seeks greater accountability for learning and research outcomes. The major milestone is for Malaysian research universities to reach the top 100 in QS global rankings. As a result, universities are becoming more aggressive in recruiting high-quality students and lecturers. An important factor in reaching this goal is the leadership of deans who are directly responsible for such outcomes. Because faculties in universities are being held accountable for academic and scholarly activities, deans are taking on an increasingly important role. The success of the faculties depends on the leadership behavior that is displayed by deans and its effectiveness on their academic, scholarly, and developmental activities. This paper addresses the issues related to leadership behavior and its relationship to the effectiveness for quality. In particular, our intention is to examine deans' leadership behavior as perceived by lecturers regarding their influence on the effectiveness for quality in a highranking public university in Malaysia.

\footnotetext{
*Authors acknowledge Humanities \& Ethics Cluster University of Malaya, Kuala Lumpur in providing grant through Research Project No. RP 014D-13 HNE.

${ }^{1}$ University of Malaya, Institute of Educational Leadership, Malaysia, sharmuco@yahoo.com

2 University of Malaya, Institute of Educational Leadership, Malaysia, darashikohamir@gmail.com

${ }^{3}$ University of Malaya, Institute of Educational Leadership, Malaysia, sushmaveera@gmail.com

${ }^{4}$ University of Malaya, Institute of Educational Leadership, Malaysia, drsathia@um.edu.my
} 
More specifically, this study aims to:

- Analyze the leadership behavior profile of deans using an extensive and diagnostic framework and

- Investigate the relationship between leadership behavior and effectiveness for quality as measured by Key performance leadership indicators for deans.

In the next section, we present literature on the constructs of leadership behavior and effectiveness for quality, followed by research methodology, data analysis, findings, discussion, conclusion and suggestions.

\section{Literature Review}

\section{Leadership in Higher Education}

The role of leadership in universities has been debated as problematic by the scholars like Lewis and Smith (1994) and Trivellas and Dargenidou (2009a, 2009b). These scholars argue that conflicts between professional and administrative authorities and unclear goals have contributed to a more confusing state, especially since higher education leadership needs to be exercised in a variety of settings (e.g., administration, academics, scholarship, consultancies, outreach). However, leadership in higher education has been attributed to relationship between those exercising leadership and their supporting colleagues (Novak, 2002). Deans are facing greater challenges due to quality assurance systems, new rules and regulations, external accreditation of degree programs, and the improvement or maintenance of global rankings. Though several strategies have been formulated by deans to address these expectations, their leadership behaviors are becoming more critical to expedite these outcomes (Askling, 2001; Trivellas \& Dargenidou, 2009a). Deans with strong leadership are capable of spearheading these changes by designing important, realistic, and achievable objectives as well as by implementing strategies leading to goal accomplishment.

However, these leaders face various challenges that include resistance to change, not only from external factors, but also from the internal environment, specifically the lecturers (Trowler, 1998). Such resistance may hamper the unit's institutional effectiveness and quality. In order to overcome such resistance, deans must encourage lecturers to discard old values and embrace new ones (Elwood \& Leyden, 2000). Although many scholars have emphasized the leadership behaviors that lead to organizational effectiveness in school systems and business (Vilkinas \& Ladyshewsky, 2011), little research in higher education has been conducted on the dean's role in program quality. Therefore, this study intends to identify the leadership behaviors to fill this research gap.

\section{Leadership Behavior}

Leadership behavior in this study is adopted from the framework constructed by Quinn, 1988, a widely-accepted framework among researchers. This influential framework has been utilized as a map for delineating organizational leadership portraits and conducting comprehensive studies (Quinn, Faerman, Thompson, \& McGrath, 2003; Trivellas \& Dargenidou, 2009b; Vilkinas \& Ladyshewsky, 2011). This framework comprises four major leadership orientations that describe eight distinct roles as shown in Table 1. The four leadership orientations are: task leadership, stability leadership, people leadership, and adaptive leadership. Task leadership focuses on productivity, accomplishment, direction, and goal clarity. Such orientation displays two types of leadership behaviors, a producer to motivate people to act and a director to clarify the expectations and establish objectives. Stability leadership focuses on stability, control, documentation, and information management. This orientation highlights the leader's monitoring and coordinating behaviors. The coordinator maintains the order, structure, and flow of systems, while the monitor ensures compliance, tracks progress, and analyses results. People leadership focuses on flexibility and internal processes. Mentoring the followers and facilitating team work are the two core behaviors. While the mentor engages in the developing people with empathy and care, the facilitator promotes collaboration, builds trust, and fosters cohesion and teamwork. Innovativeness, entrepreneurship, adaptation, and resource procurement are the main focus of adaptive leadership. The 
two core behaviors displayed by the adaptive leaders are broker and innovator. The broker obtains resources for the organization, while the innovator facilitates changes through innovation.

Table 1. Leadership Orientation and Behaviors

\begin{tabular}{ll}
\hline $\begin{array}{l}\text { Leadership } \\
\text { Orientation }\end{array}$ & $\begin{array}{l}\text { Behavioral } \\
\text { Description }\end{array}$ \\
\hline $\begin{array}{l}\text { Task leadership } \\
\text { Producer }\end{array}$ & $\begin{array}{l}\text { Motivates followers, accomplishes stated goals, and maintains high productivity } \\
\text { Director } \\
\text { Stability leadership }\end{array}$ \\
$\begin{array}{l}\text { Clarifies expectations, frames objectives, sets policies and instructs } \\
\text { Coordinator }\end{array}$ & $\begin{array}{l}\text { Leads the process, communicates and coordinates the activities } \\
\text { People Leadership }\end{array}$ \\
$\begin{array}{l}\text { Mentor } \\
\text { Facilitator }\end{array}$ & Cares about followers, shows empathy \\
Adaptive leadership & Collaborates with team members and shared decision making \\
Innovator & Explores new ideas, identifies and facilitates for change \\
Broker & Exerts influence in and out of faculty, negotiates and brings resources \\
\hline
\end{tabular}

\section{Effectiveness for Quality}

Scholars like Lindsay (1994), Tam (1999), and Trivellas and Dargenidou (2009a, 2009b), have discussed quality issues in higher education. These scholars believe that quality needs to be determined by the stake holders. In particular, a dean of a faculty has a number of stake holders, such as students, academic staff, administrative staff, society, and the university senate, all of whom may have different views about quality. Galloway (1998) argues that improvement that satisfies only external customers' perceptions and ignores internal issues may be dangerous. The majority of studies in higher education dealing with quality issues have focused on students' perceptions, while little attention has been paid to the impressions of the academic staff. Furthermore, a limited number of scholars have linked quality associated with teaching, research, and institutional development.

In this study, we focus on views of the academic staff on effectiveness for quality, based on the participating university's Key Performance Indicators (KPI) for faculty. In this particular university, deans are provided with Key Performance Indicators, $70 \%$ of which focus on achievements in academic and scholarly activities and development. The higher the fulfillment of KPIs, the higher quality is achieved. Deans are expected to assure quality through high teaching and learning standards, high quality of research that leads to publications in high impact journals, international collaboration, and continuous improvement and development. The tenure of deans depends on their effectiveness to ensure high quality, hence in this study, we intend to emphasize the aspect of effectiveness for quality. The two important measures of effectiveness that account for over $70 \%$ achievement of Key Performance Indicators and the manner these measures are described are stated in Table 2. For example, effectiveness in academic and scholarly activities are measured through descriptors like obtaining grants and funds from external sources, guiding curriculum development, stimulating research and scholarly activities in the faculty. Effectiveness in developmental activities is measured through the descriptors like guiding the development of procedures for assessing faculty performances, guiding development of faculty goals, recognizing and rewarding faculty, and maintaining high morale of faculty members through professional development activities. It is anticipated that effectiveness for quality in universities requires these leadership behaviors. Therefore, we intend to investigate which leadership behaviors adopted from Quinn (1988) predict the effectiveness for quality as expected by the top management of university from the deans through their key performance indicators. 
Table 2. Effectiveness for Quality

\begin{tabular}{ll}
\hline Effectiveness Measures & Description \\
\hline Academic \& Scholarly Activities & $\begin{array}{l}\text { Arranging effective and equitable allocation of faculty } \\
\text { responsibilities, obtaining grants and funds from external sources, } \\
\text { guiding curriculum development, stimulating research and } \\
\text { scholarly activities in the faculty fostering high quality teaching in } \\
\text { the faculty, leading recruitment of promising faculty, encouraging } \\
\text { an appropriate balance among specializations within the faculty. } \\
\text { Guiding the development of procedures for assessing faculty } \\
\text { performances, recognizing and rewarding faculty in accordance } \\
\text { with their contribution to the faculty, guiding development of } \\
\text { plans to accomplish organizational goal, understanding and } \\
\text { communicating expectations of top management to the faculty and } \\
\text { vice-versa, improving the faculty's image and reputation in the } \\
\text { university, developing each faculty member's talents or interests, } \\
\text { maintaining faculty morale through various professional } \\
\text { development activities. }\end{array}$ \\
\hline
\end{tabular}

\section{Methodology}

The study used an exploratory survey method to examine leadership behaviors and their influence on effectiveness for quality. Such exploratory studies are appropriate to study this phenomenon, which has been neglected and requires better conceptualization (Ndirangu \& Udoto, 2011).

A sample of 400 respondents was selected from eight faculties of a high-ranking Malaysian university with a population of around 3500 teaching staff from twelve faculties. Fifty (50) faculty members were randomly selected from each of the eight faculties. The sample size was sufficient enough for such a large population, including provisions for non-responses (Krejcie \& Morgan, 1970). We began with purposive sampling to select eight faculties, followed by systematic sampling to select academic staff members in the faculty. Thus, a maximum sample size of 50 academic staff members for each of the eight faculties was obtained. A self-developed questionnaire was administered to these respondents. The questionnaire was pretested and a pilot study was carried out in a public university in Malaysia which was not part of this study. Cronbach alpha was used to test internal consistency.

\section{Data Collection Tool}

The study utilized a self-developed questionnaire titled 'Leadership behavior and effectiveness for quality'. As discussed earlier, the leadership behavior construct was adopted from the leadership role construct by Quinn (1988) and the effectiveness for quality measured the Key Performance Indicators used by deans and directors. The leadership behavior construct has four leadership orientations each comprising two different types of behaviors, as shown in Table 1. These orientations are task leadership, stability leadership, people leadership, and adaptive leadership. The behaviors associated with task leadership are producer and director; with stability leadership are coordinator and monitor; with people leadership are facilitator and mentor; and with adaptive leadership are innovator and broker. These constructs are measured by 22 items using an 11 point scale (Hair, Black, Babin, Anderson, \& Tatham, 2010), where 0 indicates almost never descriptive about dean and 10 almost always descriptive about dean. The effectiveness for quality construct comprises two dimensions: effectiveness in academic and scholarly activities; and effectiveness in developmental activities, as shown in Table 2. The former dimension has seven items while the latter has eight. These items were also measured using an 11 point scale, where 0 indicates almost never descriptive about dean and 10 almost always descriptive about dean. 


\section{Analysis of Data}

We used Cronbach's alpha to examine Internal consistency. We then analyzed data using principal component analysis with varimax rotation to extract factor loadings and dimensions, followed by multiple regression analysis. Before using analytical methods, we reviewed normality, multicorrelation, validity, and reliability of constructs. Variance inflation factor (VIF) was calculated to verify absence of multi-collinearity by examining the recommended threshold of variance inflation factors values less than ten ( Hair et al.,2010). The VIF values were all acceptable with a score of 2.0.

\section{Results}

\section{Principal Component Analysis}

Principal Component Analysis was conducted for both constructs -- leadership behavior and effectiveness for quality. For leadership behavior, eight factors were extracted from the data. These principal components accounted for 92 percent of the total variation. Similarly, for effectiveness for quality, two factors were extracted, accounting for 91.4 percent of the total variation. The degree of correlation between the variables was calculated using Bartlett sphericity $(\mathrm{p}<.001)$ and appropriateness of the sample according to the Kaiser -Meyer-Olkin index $(\mathrm{KMO}<0.85)$.

Inter-item analysis was used to verify internal consistency or reliability for leadership behavior and effectiveness for quality items. In particular, Cronbach's alpha was calculated for each scale, as recommended by Hair et al. (2010), ranging from .796 to .955 (refer to Table 3?). Thus, all sub scales exhibited well over minimum acceptable reliability level of 0.7 .

Descriptive statistics analysis shows that dominant leadership behavior shown by the deans is of director (M/SD; 6.38/1.254) and the least is innovator (M/SD; 4.22/1.673). In terms of effectiveness for quality, the dominant effectiveness is indicated for academic and scholarly activities (M/SD; 4.75/1.352) while developmental activities are far behind (M/SD; 3.53/1.571).

Table 3. Descriptive Statistics and Internal Reliability of All Scales

\begin{tabular}{llllll}
\hline & Mean & SD & Items & Cronbach Alpha & KMO \\
\hline Leadership Behavior & & & & & 0.864 \\
Broker & 4.58 & 1.324 & 3 & .932 & \\
Coordinator & 6.25 & 1.545 & 3 & .921 & \\
Director & 6.38 & 1.254 & 2 & .942 & \\
Facilitator & 5.36 & 1.012 & 2 & .851 & \\
Innovator & 4.22 & 1.673 & 4 & .796 & \\
Mentor & 5.84 & 1.041 & 2 & .824 & \\
Monitor & 4.86 & 1.156 & 3 & .955 & \\
Producer & 6.15 & 1.245 & 3 & .911 & \\
Effectiveness for Quality & & & & & \\
Scholarly Activities & 4.75 & 1.352 & 7 & .948 & \\
Developmental Activities & 3.53 & 1.571 & 8 & 932 & \\
\hline
\end{tabular}

\section{Multiple Regression Analysis}

Multiple regression analysis was conducted for each of the dimensions of effectiveness for quality as dependent variable, analyzing their relationship with leadership behavior and gender, age, and experience as control variables (see Table 4). The predictor variables accounted for a significant proportion of change in the dependent variable, explaining $52.5 \%$ of variance in academic and scholarly activities and $42.2 \%$ of variance in developmental activity. 
In terms of influence of predictor variables and the scholarly dimension activities, the standardized betas reveal that coordinator (strand, $\beta=0.331$ ), facilitator (strand, $\beta=0.521$ ), mentor (strand, $\beta=0.339$ ), and monitor (strand, $\beta=0.364$ ) are significantly and positive predictors of the scholarly activities aspect of effectiveness for quality. Similarly, in terms of effects of predictor variables and dimension the developmental activities dimension, the standardized betas reveal that coordinator (strand, $\beta=0.342$ ), director (strand, $\beta=0.221$ ), facilitator (strand, $\beta=0.415$ ), mentor (strand, $\beta=0.321$ ) and monitor (strand, $\beta=0.229$ ) are significantly and positive predictors of the developmental activities aspect of effectiveness for quality.

Table 4. Regression Models for the Relationships of Leadership Behavior and Effectiveness of Quality

\begin{tabular}{lcc}
\hline \multirow{2}{*}{ Independent Variable } & \multicolumn{2}{c}{ Effectiveness } \\
\cline { 2 - 3 } & Scholarly activities & Developmental activities \\
\hline Control Variables & $\beta$ & $\beta$ \\
\hline Gender & 0.012 & 0.054 \\
Age & 0.065 & 0.072 \\
Experience & 0.033 & 0.024 \\
Leadership Behavior & & \\
Broker & 0.225 & 0.128 \\
Coordinator & $0.331^{*}$ & $0.342^{*}$ \\
Director & 0.145 & 0.221 \\
Facilitator & $0.521^{* *}$ & $0.415^{* *}$ \\
Innovator & 0.092 & 0.188 \\
Mentor & $0.339^{*}$ & $0.321^{*}$ \\
Monitor & $0.364^{*}$ & $0.229^{*}$ \\
Producer & 0.132 & 0.176 \\
Adjusted $\mathrm{R}^{2}$ & $0.525^{* *}$ & $0.422^{* *}$ \\
\hline
\end{tabular}

${ }^{*} 0.05,{ }^{* *} 0.01, \mathrm{n}=400$

\section{Discussion}

This study aims to examine the leadership behavior of deans and its influence on effectiveness for the quality in a high-ranking public university in Malaysia. Findings reveal that the dominant leadership behaviors displayed by the deans are being directors and coordinators. Both types of behaviors are control oriented and the leaders who display such behaviors are task and stability oriented. The director sets priorities and the directions for the faculty and communicates the goals to the faculty. On the other hand, the coordinator coordinates the activities related to goals and ensures smooth functioning of the system through his/her flexibility in decision making according to the situation.

Findings also reveal that the third important leadership behavior displayed by deans is producer. This indicates deans set the goals for the faculty, motivate them to accomplish the goal, and lead the process of goal accomplishment. The preponderance of the director and producer roles of deans suggests they are task oriented and prefer stability and rigidity in their faculty. The importance of task oriented leadership is highly advocated by Dunn, Gerlach and Hyle (2014), who have found taskoriented female academic leaders to be more successful in setting the goals for their faculty, motivating followers to accomplish the goals, and leading the process of goal accomplishment. 
The fourth and fifth important leadership behaviors displayed by deans are mentor and facilitator respectively. This suggests deans care about their followers, show empathy towards them, work collaboratively, and prefer shared decision-making processes. Such behaviors are regarded as people orientation, indicating deans want to facilitate the commitment of followers towards the organization and its leadership. Steward (2009) found that academic leaders who work collaboratively with their lecturers and demonstrate concern for them establish trust and in return win their favor for goal accomplishment.

We also investigated innovator and broker leadership behaviors; however, they were the least evident actions of this sample of deans. This reflects that the deans as leaders lack adaptability. Such deans are reluctant to explore new ideas, implement innovations, lead change, exert influence to secure resources, and negotiate resources for the faculty. These findings are in line with those of earlier researchers (Trivellas \& Dargenidou, 2009a, 2009b; Hooijberg \& Choi, 2000) who contend public universities reflect highly bureaucratic cultures based on strict rules and control, and their leaders follow highly-conservative and stability-oriented roles.

In terms of effectiveness for quality, the findings reveal that the deans are found to be more focused on academic and scholarly activities rather than developmental activities. However, their overall effectiveness is found to be negatively skewed which is in agreement with earlier findings by Scott, Coates and Anderson (2008) and Vilkinas and Ladyshewsky (2011). Since many Malaysian universities are striving to achieve high international rankings, most of the efforts by the deans focus on securing research grants and recruiting highly-promising faculty members who can provide excellent teaching and produce high-quality research and publications. However, deans tend to avoid developmental activities, such as developing faculty members' interests, communicating faculty's concerns to higher management, and maintaining high morale of faculty through various professional development activities.

Our investigation identified the four leadership behaviors - coordinator, facilitator, mentor and monitor, to be significant predictors of dimensions of leadership effectiveness for quality. The coordinator behavior of deans is strongly related to their effectiveness for quality in academic and scholarly activities by obtaining resources for the faculty, arranging effective and equitable allocation for lecturers, developing team members' interests, stimulating research and publications, and fostering high-quality teaching by hiring competent lecturers with balanced specializations. Similarly, the coordinator behavior of deans is strongly related to their effectiveness for quality in developmental activities because it supports the development of plans and procedures to accomplish organizational goals and faculty performance assessments, communicates top managements' expectations to faculty and vice versa, improves faculty image across the university, and maintains faculty morale through professional development activities. Other researchers (Hart \& Quinn, 1993; Hooijberg, 1996; Hooijberg \& Choi, 2000; Osseo-Asare, Longbottom, \& Murphy, 2005; Smart, 2003; Trivellas \& Dargenidou, 2009a, $2009 \mathrm{~b}$ ) also have identified the four leadership behaviors as significant predictors of the dimensions of leadership effectiveness

Through our investigation we also found the monitoring leadership behaviors of deans have significant influence on the dimensions of leadership effectiveness for quality. Deans monitor the process of goal accomplishment, identify the bottlenecks in the process and remove them, and monitor success, all of which are deemed to be quite supportive in their leadership effectiveness for quality towards academic, scholarly, and developmental activities. The stability-oriented behaviors of coordinating and monitoring positively influences the leadership effectiveness for quality as noted by Quinn et al. (2003), Trivellas and Dargenidou (2009a, 2009b), and Vilkinas and Ladyshewsky (2011). 
Further adding to our findings, we discovered facilitator and mentor behaviors as significant predictors for effectiveness of quality. Working to collaborate with faculty members and involving them in decision making processes (facilitator behavior) as well as caring for them and showing empathy (mentor behavior) undoubtedly reflect people-oriented leadership effectiveness for the academic and scholarly development of faculty. These findings are in accordance with research conducted by Trivellas and Dargenidou (2009a), Shamir, House, and Arthur (1993), and Sternberg (2005). In contrast, we found little evidence of any significant influence of producer and director (task leadership) and innovator and broker (adaptive leadership) on the effectiveness dimensions. Such leadership orientations are argued to be essential for $21^{\text {st }}$ century higher education institutions by scholars like Bornstein (2007) and Lipman-Bluman (1992), who believe that in the highly-competitive and rapidly-changing global economy, institutional leadership should be innovative and flexible. Our study has shown that the effectiveness of the institution is predicted by people-oriented and stability-oriented leadership, which is in line with assertion of Dunn et al. (2014) and Steward (2009).

\section{Discussion}

To recapitulate, our results indicate that stability-oriented leadership behavior and peopleoriented leadership behaviors are linked to the effectiveness for the quality of academic and scholarly developmental activities. Our findings clearly indicate that the deans in this particular high-ranking university display a variety of leadership behaviors although to a different degree. Their stability orientation and people orientation successfully influences their effectiveness for quality which is in line with the research by Dunn et al. (2014), Hart and Quinn (1993), Hooijberg (1996), Hooijberg and Choi (2000), Osseo-Asare et al. (2005), Smart (2003), Steward (2009), and Trivellas and Dargenidou (2009a, 2009b). However, a variety of scholars, like Denison, Hooijberg, and Quinn (1995), Hooijberg and Choi (2000), and Smart (2003), support the display of a wide range of behaviors by leaders. On the other hand, Trivellas and Dargenidou (2009a), Shamir et al. (1993), and Sternberg (2005) advocate for limiting leadership behaviors that are vital for effectiveness. This study expands our understanding of deans' leadership behaviors by matching their behaviors with various effectiveness dimensions. As advocated by Mosadeghard (2006), improvement of higher education quality depends on the organization's ability to create a culture of change, which is highly dependent on the effectiveness of leadership.

Although our study links leadership behavior with effectiveness, we suggest additional studies be conducted to link leadership behaviors, leadership effectiveness for quality, and quality in higher education to contribute to the on growing literature on higher education leadership and the influence of gender based leadership on effectiveness. Because a major limitation of this study is that it is a purely quantitative study based on perceptions of faculty members from only one university and didn't account for influence of gender, generalizations to other institutional settings cannot be made nor influence of gender can be argued. It is therefore recommended to expand the sample by incorprating various universities in Malaysia and compare gender in leadership to better understand the cultural context of the country. Since public universities around the world are confronting a variety of issues like globalization, accountability, competition, and global ranking, further research should be conducted in private and public universities in Malaysia and other countries to allow cross-national comparisons.

\section{Acknowledgements}

Authors want to acknowledge Prof. Bruce G. Barnett, University of Texas at San Antonio for editing this paper. 


\section{References}

Askling, B. (2001). In search of new models of institutional governance: Some Swedish experiences. Tertiary Education and Management, 7(2), 197-210.

Bornstein, R. (2007). Why women make good college presidents. Residency, 10(2), 20-23

Denison, D. R., Hooijberg, R., \& Quinn, R. E. (1995). Paradox and performance: Toward a theory of behavioral complexity in managerial leadership. Organization Science, 6(5), 524-540.

Dunn, D., Gerlach, J. M., \& Hyle, A. E. (2014). Gender and leadership: Refelections of women in higher education administration. International Journal of Leadership \& Change, 2(1), 9-18

Elwood, L. P., \& Leyden, V. M. (2000). Strategic planning and cultural considerations in tertiary education systems: The Irish case. Scandinavian Journal of Educational Research, 44(3), 308-323.

Galloway, L. (1998). Quality perceptions of internal and external customers: A case study in educational administration. The TQM Magazine, 10(1), 20-26.

Hair, J. F., Black, W. C., Babin, B. J., Anderson, R. E., \& Tatham, R. L. (2010). Multivariate data analysis (7th ed.). Upper Saddle River, NJ: Pearson Education International.

Hart, S. L., \& Quinn, R. E. (1993). Roles executives play: CEO, behavioral complexity and firm performance. Human Relations, 46(5), 543-576

Hooijberg, R. (1996). A multidirectional approach toward leadership: An extension of the concept of behavioral complexity. Human Relations, 49(7), 917-946.

Hooijberg, R., \& Choi, J. (2000). Which leadership matters to whom? An examination of rater effects on perception of effectiveness. Leadership Quarterly, 11(3), 341-364.

Krejcie, R. V., \& Morgan, D. W. (1970). Determining sample size for research activities. Educational and Psychological Measurements, 30, 607-610.

Lewis, R. G., \& Smith, D. H. (1994). Total quality in higher education. Delray Beach, FL: St. Lucie Press.

Lindsay, A. (1994). Quality and management in universities. Journal of Tertiary Education Administration, 16(1), 55-68.

Lipman-Bluman, J. (1992). Connective leadership: Female leadership styles in $21^{\text {st }}$ century work place. Sociological Perspectives, 35(1), 183-203.

Mosadeghard, A. M. (2006). The impact of organizational culture on the successful implementation of total quality management. The TQM Magazine, 18(6), 606-625.

Ndirangu, M., \& Udoto, M. O. (2011). Challenges for teaching and learning in Kenya's public universities. Quality Assurance in Education, 19(3), 208-223.

Novak, J. M. (2002). Inviting educational leadership: Fulfilling potential and applying on ethical perspective to the educational process. London: Pearson Education.

Osseo-Assare, A. E., Longbottom, D., \& Murphy, W. D. (2005). Leadership best practices for sustaining quality in UK higher education from the perspective of the EFQM excellence model. Quality Assurance in Education, 13(2), 148-170.

Quinn, R. E. (1988). Beyond rational management. San Francisco: Jossey-Bass.

Quinn, R. E., Faerman, S. R., Thompson, M. P., \& McGrath, M. R. (2003). Becoming a master manager (3rd ed.). New York, NY: Wiley.

Scott, G., Coates, H., \& Anderson, M. (2008). Learning leaders in times of change: Academic leadership capabilities for australian higher education. Surry Hills, New South Wales: Australian Learning and Teaching Council.

Shamir, B., House, R. J., \& Arthur, M. B. (1993). The motivational effects of charismatic leadership: A self-concept based theory. Organizational Science, 4(2), 577-594.

Smart, J. C. (2003). Organizational effectiveness of 2-year colleges: The centrality of cultural and leadership complexity. Research in Higher Education, 44(6), 673-703. 
Sternberg, R. J. (2005). A model of educational leadership: Wisdom, intelligence, and creativity, synthesized. International Journal of Leadership in Education, 8(4), 347-364.

Steward, J. M. (2009). Common characteristics of women leaders in higher education administration (Master's thesis). Department of Planning, Public Policy and Management, University of Oregon, Eugene, OR.

Tam, M. (1999). Quality assurance policies in higher education in Hong Kong. Journal of Higher Policies and Management, 21(2), 215-226.

Trivellas, P., \& Dargenidou, D. (2009a). Organizational culture, job satisfaction and higher education service quality: the case of technological educational institute of Larissa. The TQM Journal, 21(4), 382-389.

Trivellas, P., \& Dargenidou, D. (2009b). Leadership and service quality in higher education: the case of technological educational institute of Larissa. International Journal of Quality and Service Sciences, 1(3), 294-311.

Trowler, P. (1998). Academic responding to change: New higher education framework and academic cultures. Buckingham: Society for Research into Higher Education \& Open University Press.

Vilkinas, T., \& Ladyshewsky, R. K. (2011). Leadership behavior and effectiveness of academic program directors in Australian Universities. Educational Management, Administration \& Leadership, 40(1), 109-126. 